\title{
Lack of a Major Role of Staphylococcus aureus Panton-Valentine Leukocidin in Lower Respiratory Tract Infection in Nonhuman Primates
}

\author{
Randall J. Olsen, ${ }^{, \dagger}$ Scott D. Kobayashi, ${ }^{\neq}$ \\ Ara A. Ayeras, ${ }^{*}$ Madiha Ashraf, ${ }^{* \S}$ \\ Shawna F. Graves, ${ }^{\ddagger}$ Willie Ragasa, ${ }^{*}$ \\ Tammy Humbird, " Jamieson L. Greaver, \\ Constance Cantu, ${ }^{*}$ Jody L. Swain," \\ Leslie Jenkins, ${ }^{* \star}$ Terry Blasdel, ${ }^{\text {Tा }}$ Philip T. Cagle, ${ }^{*}$ \\ Donald J. Gardner, ${ }^{+\dagger}$ Frank R. DeLeo, ${ }^{\ddagger}$ \\ and James M. Musser*

\begin{abstract}
From the Center for Molecular and Translational Human Infectious Diseases Research," and the Comparative Medicine Methodist Hospital, Houston, Texas; the Departments of Pathology, ${ }^{\dagger}$ and Medicine, ${ }^{\S}$ the Methodist Hospital, Houston, Texas; the Laboratory of Human Bacterial Pathogenesis, ${ }^{\ddagger}$ and the Veterinary Branch," Rocky Mountain Laboratories, National of Health, Hamilton, Montana; Animal Care Operations, Division of Research, "Tniversity of Houston, Texas; and the Center for Comparative Medicine,** Baylor College of Medicine, Houston, Texas
\end{abstract} \\ Program, ${ }^{+\dagger}$ The Methodist Hospital Research Institute, the \\ Institute of Allergy and Infectious Diseases, National Institutes
}

Panton-Valentine leukocidin (PVL) is a two-component cytolytic toxin epidemiologically linked to community-associated methicillin-resistant Stapbylococcus aureus (CA-MRSA) infections, including serious invasive infections caused by the epidemic clone referred to as strain USA300. Although PVL has long been known to be a $S$. aureus virulence molecule in vitro, the relative contribution of this leukotoxin to invasive CA-MRSA infections such as pneumonia remains controversial. We developed a nonhuman primate model of CA-MRSA pneumonia and used it to test the hypothesis that PVL contributes to lower respiratory tract infections caused by $S$. aureus strain USA300. The lower respiratory tract disease observed in this monkey model mimicked the clinical and pathological features of early mild to moderate $S$. $a u$ reus pneumonia in humans, including fine-structure histopathology. In this experiment using a large sample of monkeys and multiple time points of examination, no involvement of PVL in virulence could be de- tected. Compared with the wild-type parental USA300 strain, the isogenic PVL deletion-mutant strain caused equivalent lower respiratory tract pathology. We conclude that PVL does not contribute to lower respiratory tract infection in this nonhuman primate model of human CA-MRSA pneumonia. (Am J Pathol 2010, 176:1346-1354; DOI: 10.2353/ajpath.2010.090960)

Staphylococcus aureus is the most abundant cause of serious bacterial infections in the United States. ${ }^{1-4}$ In addition, the organism acquires antibiotic resistance readily and methicillin-resistant S. aureus (MRSA) strains have been a major concern in health care facilities for decades. ${ }^{3-7}$ The pathogen causes a wide spectrum of infections, ranging from mild skin problems to fatal invasive diseases. ${ }^{1}$ The mortality rate associated with invasive MRSA infections is approximately $20 \%$, the majority of which are health careor hospital-associated. ${ }^{1}$ Inasmuch as health care-associated S. aureus infections occur in individuals with predisposing risk factors, the health status of the patient plays a prominent role. In contrast, community-associated MRSA (CA-MRSA) strains generally cause infections in otherwise healthy individuals.

CA-MRSA emerged unexpectedly in the 1990s and is now epidemic in the United States. ${ }^{2,8,9}$ The prototype CA-MRSA strain in the United States, known as pulsedfield type USA400 (MW2), caused fatal pneumonia in children in the Midwest. ${ }^{10,11}$ Whole-genome sequencing of a USA400 strain revealed the presence of a novel methicillin-resistance element SCCmecIV and lukS-PV and lukF-PV (lukS/F-PV) genes encoding a two-component cytolytic toxin known as Panton-Valentine leukocidin (PVL). ${ }^{12}$

Supported by American Heart Association Fellow-to-Faculty Transition Award (to R.J.O.) and Intramural Research Program of the National Institutes of Health, National Institute of Allergy and Infectious Diseases.

Accepted for publication November 17, 2009.

Address reprint requests to Dr. James M. Musser, Center for Molecular and Translational Human Infectious Diseases Research, The Methodist Hospital Research Institute, B490, 6565 Fannin Street, Houston, TX 77030. E-mail: jmmusser@tmhs.org. 
Although strains of USA400 remain a significant cause of CA-MRSA infections, especially in Canada, ${ }^{13,14}$ they have been nearly replaced in the United States by the pulsedfield type USA300 epidemic clone (USA300). ${ }^{9,15,16}$ Notably, SCCmecIV and PVL genes are also present in the genome of USA300, ${ }^{17}$ and thus, they are strongly linked by epidemiology to CA-MRSA infections in the United States. The great majority of USA300 infections involve skin and soft tissue, accounting for $75 \%$ to $95 \%$ of CA-MRSA infections. ${ }^{8,16,18,19}$ However, this pathogen also has the ability to cause severe invasive disease, including cases of fatal pneumonia. ${ }^{20,21}$

Several lines of evidence suggest that PVL may be an important virulence factor in the pathogenesis of $S$. aureus pneumonia. Lina and colleagues first described an association of PVL with $S$. aureus strains that cause primary community-acquired pneumonia, some of which were fatal cases of necrotizing pneumonia. ${ }^{22}$ Subsequently, PVL-producing S. aureus, mostly methicillin-susceptible $S$. aureus strains, were reported to be associated with necrotizing pneumonia in young immunocompetent individuals. ${ }^{23}$ Recent reports also document that PVL-positive strains of USA300 can cause necrotizing pneumonia, albeit these infections are infrequent and often associated with influenza or parainfluenza virus coinfection. ${ }^{24}$

Despite the epidemiological linkage, there is currently little direct experimental evidence that PVL is a primary virulence factor for CA-MRSA pneumonia. One study suggested that $\mathrm{PVL}$ promotes $S$. aureus pneumonia in a mouse infection model. ${ }^{25}$ However, subsequent work by several investigators using wild-type USA300 and USA400 and isogenic PVL deletion mutant strains failed to support the idea that PVL contributes to experimental CA-MRSA pneumonia in mice or rats. ${ }^{26-29}$

Elucidating whether PVL has a role in pneumonia in humans is critical because the leukotoxin is widely considered to be a possible determining factor in CA-MRSA pneumonia, and therefore, it has become a target for antistaphylococcal therapeutics and vaccines. ${ }^{30} \mathrm{We}$ developed a nonhuman primate model of $S$. aureus lower respiratory tract infection and used it to test the hypothesis that USA300 wild-type and isogenic PVL mutant strains differ in their ability to cause CA-MRSA pneumonia.

\section{Materials and Methods}

\section{Bacterial Strains}

USA300 wild-type and isogenic lukS/F-PV deletion mutant strains (LAC and LAC $\Delta p v /$ ) were described previously. ${ }^{31}$ To approximate $S$. aureus in saliva, strains were cultured in trypticase soy broth to late-stationary phase. Bacteria were collected by centrifugation, washed three times with phosphate-buffered saline (PBS), and frozen in multiple aliquots at $-80^{\circ} \mathrm{C}$ in PBS containing $10 \%$ glycerol at a calculated concentration of $8 \times 10^{8} \mathrm{CFU} / \mathrm{ml}$. The concentration of these frozen stocks was confirmed by quantitative culture of three aliquots of each strain. To prepare inocula immediately before bronchoscopic instillation, one aliquot of each strain was thawed on wet ice and diluted to $1 \times 10^{6} \mathrm{CFU} / \mathrm{ml}$ in sterile PBS. The CFUs in each inoculum were confirmed by quantitative culture.

\section{Monkey Infection}

Twelve male cynomolgus macaques (Macaca fasicularis; Charles River BRF, Houston, Texas), age 3 to 4 years and weight 4 to $5 \mathrm{~kg}$, were formulated into three cohorts of four animals and randomly assigned to receive wild-type or $\Delta p v l$ USA300 strains. For experimental infections, a bronchoscope (Richard Wolf Medical Instruments, Vernon Hills, IL) was passed into the trachea of anesthetized animals and positioned into the first bronchiole of the lateral bronchiole system that forms the right middle lobe. After instillation of $1 \times 10^{6} \mathrm{CFU}$ in $1 \mathrm{ml} \mathrm{PBS}$, the bronchoscope was flushed with $1 \mathrm{ml}$ PBS and $1 \mathrm{ml}$ air. Animals were housed individually, provided food and water ad libitum, and observed hourly by trained veterinary staff. Two randomly selected animals from each strain treatment group were sacrificed at 2-day, 4-day, and 8-day postinoculation. The preinfection and perimortem examinations included vital sign measurement, pulmonary auscultation, and phlebotomy. Investigators were blinded until completion of all data analyses. The study protocol was approved by the Animal Care and Use Committee, University of Houston and Rocky Mountain Laboratories, NIAID.

\section{Monkey Anesthesia and Sedation}

For bronchoscopy, animals were sedated with $2 \mathrm{mg} / \mathrm{kg}$ tiletamine- $\mathrm{HCl}$ and zolazepam- $\mathrm{HCl}$ (Fort Dodge Animal Health, Overland Park, KS) and treated with $30 \mu \mathrm{g}$ fentanyl (Hospira, Lake Forest, IL) and $0.9 \mu \mathrm{g}$ glycopyrrolate (Baxter Healthcare, Deerfield, IL) intramuscularly. Analgesia was provided by a $25 \mu \mathrm{g} / \mathrm{h}$ transdermal fentanyl patch (Sandoz, Princeton, NJ). For necropsy, animals were sedated with $5 \mathrm{mg} / \mathrm{kg}$ tiletamine- $\mathrm{HCl}$ and zolazepam- $\mathrm{HCl}$ and euthanized with $3 \mathrm{ml}$ Euthasol (Virbac, Fort Worth, TX).

\section{Gross and Microscopic Pathological Analyses}

Tissues collected at necropsy were examined by one or more pathologists. A lung gross pathology score was calculated based on five criteria, each semiquantitatively scored on a scale of 0 to 1 , including: 1 and 2) discoloration of the right and left lung surface or cut margin; 3 and 4) consolidation of the right and left lung parenchyma; and 5) increased lung mass. After scoring, the left and right lungs were removed. The right lung was inflated with $10 \%$ phosphate-buffered formalin and fixed for 48 hours before histological processing. The left lung and abdominal organs were serially sectioned and inspected for infection or other pathological abnormality. Tissue for microscopic examination was fixed, decalcified when ap- 
propriate, and embedded in paraffin using automated standard instruments. Hematoxylin and eosin-, Gram-, and immunoperoxidase- (Dako, Carpinteria, CA) stained sections were examined with a BX5 microscope and photographed with a DP70 camera (Olympus America Center Valley, PA). Lung histopathology was assessed independently by two pathologists who were blinded to the strain treatment groups and sacrifice time. A mean lung microscopic pathology score was calculated for the right lobe based on three criteria, each semiquantitatively scored on a scale of 0 to 4 per slide, including: 1) severity of acute pneumonia; 2) severity of interstitial pneumonia; and 3) proportion of arteries with perivascular induced bronchus-associated lymphoid tissue (IBALT).

\section{Quantitative Bacterial Culture from Infected Monkey Tissue}

For quantitative bacterial culture of the left lung (contralateral to the side of inoculation), five representative portions of tissue (one from the upper lobe and two each from the middle and lower lobes), each measuring approximately $0.5 \mathrm{~cm}$ and weighing 0.2 to $0.5 \mathrm{~g}$, were homogenized (Omni, USA Scientific, Ocala, FL) in $3 \mathrm{ml}$ sterile PBS, weighed, diluted serially, and inoculated in duplicate on tryptic soy agar plates supplemented with $5 \%$ sheep blood (Remel Products, Lenexa, KS). Alternatively, recovered isolates were subcultured on BBL CHROMagar MRSA (BD Diagnostic Systems, Sparks, $\mathrm{MD})$ to identify MRSA. The plates were incubated for 24 hours at $37^{\circ} \mathrm{C}$, and CFUs per Gram of tissue were calculated. Qualitative blood cultures were performed using Bactec media (Becton Dickinson and Co, Franklin Lakes, NJ).

\section{Analysis of Cell Counts, Cytokines, and Bioactive Molecules}

Cell counts, chemistry profiles, and coagulation tests were performed by automated standard methods (Equine Laboratories, Houston, TX). Quantitative multianalyte testing was performed on serum using the HumanMAP v1.6 immunoassay (Rules Based Medicine, Austin, TX). MPO concentration was assayed on homogenized lung tissue samples using the Zen-Myeloperoxidase kit (Molecular Probes, Life Technologies, Carlsbad, CA).

\section{Statistical Analysis}

For all measured parameters of virulence, statistical comparisons between strain treatment groups at each time point were made using the Mann-Whitney test (twotailed, $P<0.05$ considered significant). Statistical comparisons between strain treatment groups across all time points were made by one-way AVOVA. Statistical comparisons between data pooled for each strain treatment group independent of the time point were made using the Mann-Whitney test.

\section{Results \\ Lower Respiratory Tract Infection of Cynomolgus Macaques}

S. aureus expresses several molecules whose role in virulence may vary depending on the animal species, which means that disease models using rodents and other lower vertebrate species such as rabbits may not fully recapitulate human infections. ${ }^{32,33}$ Our recent studies with group A Streptococcus indicated that after lower respiratory tract inoculation, cynomolgus macaques developed pneumonia that was histologically indistinguishable from human disease (R.J. Olsen et al, in preparation). Therefore, we used a similar lower respiratory tract infection model to evaluate USA300 virulence and the role of $P V L$ in pneumonia. Twelve adult animals were inoculated via bronchoscopic installation into the right middle lobe of the lung with a relatively low dose $(n=6$ animals per strain treatment group, each inoculated with $10^{6} \mathrm{CFUs}$ ) of either wild-type or isogenic lukS/F-PV deletion-mutant $(\Delta p v /)$ strains of USA300. ${ }^{31}$ This dose of bacteria was selected because it approximates the number of $S$. aureus CFUs that can be present in aspirated saliva. ${ }^{34}$ We used strain LAC because it is genetically representative of the epidemic USA300 clone, is highly virulent, and has been used extensively in other pathogenesis experiments. ${ }^{28,29,31,35-37}$

The 12 animals were assessed for disease progression as described below. Necropsies were performed on two monkeys from each strain treatment group (wild-type and $\Delta p v($ strains) at 2-day, 4-day, and 8-day postinoculation. Multiple clinical, pathological, microbiological, and molecular assays were used to assess severity of the resulting lower respiratory tract infection.

\section{Clinical Assessment of MRSA-Infected Monkeys}

Personnel performing clinical assessments were blinded to the strain (wild-type or $\Delta p v /$ strain) used to infect each animal. Analysis of the clinical data collected during the postinoculation observation period provided strong evidence that all 12 monkeys developed a significant lower respiratory tract infection. Each monkey had nonspecific signs of infection such as decreased food intake, increased daytime somnolence, and an infrequent nonproductive cough. Importantly, perimortem examination showed markedly altered pulmonary function in all animals (Table 1). Most monkeys had bilateral coarse breath sounds and basilar wheezes, more prominent over the right middle (instillation site) and lower lung lobe during expiration, indicative of airway obstruction. Many also had decreased hemoglobin oxygen saturation as measured by pulse oximetry, indicating a defect in gas exchange across the alveolar membranes. Furthermore, compared with their baseline values, several monkeys in each treatment group had an increased serum fibrinogen concentration and decreased white blood cell count, suggestive of an acute phase immune response and granulocyte priming with margination or redistribution, 
Table 1. Clinical-Pathological Data of Infected Animals

\begin{tabular}{|c|c|c|c|c|c|c|c|}
\hline $\begin{array}{c}\text { Time } \\
\text { postinfection }\end{array}$ & $\begin{array}{l}\text { Strain } \\
\text { treatment } \\
\text { group }\end{array}$ & $\begin{array}{l}\text { Decreased } \\
\text { pulse } \\
\text { oximetry }\end{array}$ & $\begin{array}{l}\text { Positive } \\
\text { lung } \\
\text { ascultation }\end{array}$ & $\begin{array}{c}\text { Decreased } \\
\text { white blood cell } \\
\text { count }\end{array}$ & $\begin{array}{l}\text { Increased } \\
\text { plasma } \\
\text { fibrinogen }\end{array}$ & $\begin{array}{l}\text { CFU recovered from } \\
\text { contralateral lung } \\
\text { (CFU/g lung tissue) }\end{array}$ & $\begin{array}{c}\text { Positive } \\
\text { qualitative } \\
\text { blood culture }\end{array}$ \\
\hline \multirow[t]{2}{*}{ Day 2} & Wild-type & $1 / 2$ & $2 / 2$ & $2 / 2$ & $2 / 2$ & $0 / 2(0)$ & $0 / 2$ \\
\hline & $\Delta p v l$ & $1 / 2$ & $1 / 2$ & $2 / 2$ & $0 / 2$ & $1 / 2(398)$ & $0 / 2$ \\
\hline \multirow[t]{2}{*}{ Day 4} & Wild-type & $0 / 2$ & $2 / 2$ & $1 / 2$ & $2 / 2$ & $2 / 2(54)$ & $0 / 2$ \\
\hline & $\Delta p v l$ & $1 / 2$ & $2 / 2$ & $1 / 2$ & $2 / 2$ & $1 / 2(16)$ & $1 / 2$ \\
\hline \multirow[t]{2}{*}{ Day 8} & Wild-type & $2 / 2$ & $1 / 2$ & $2 / 2$ & $0 / 2$ & $0 / 2(0)$ & $0 / 2$ \\
\hline & $\Delta p v l$ & $1 / 2$ & $2 / 2$ & $1 / 2$ & $2 / 2$ & $2 / 2(97)$ & $0 / 2$ \\
\hline
\end{tabular}

Numbers at each time point refer to the fraction of animals in each strain treatment group demonstrating the clinical-pathological feature. Significant alterations were defined as pulse oximetry less than $96 \%$ (baseline equaled $98 \%$ to $100 \%$ ), peripheral white blood cell count decreased by at least $0.5 \times 10^{3} / \mathrm{ml}$, and fibrinogen increased by at least $50 \mathrm{mg} / \mathrm{dl}$. For CFU recovered from the left lung (contralateral to the side of inoculation), the mean (CFU/g tissue) is also shown. Note that the lower limit of detection for bacterial recovery from lung tissue in the assay used is $\approx 30$ to 40 CFU/g Qualitative blood cultures were also performed on each animal at the time of necropsy.

respectively (Table 1). These clinical features mimic those observed in humans with mild $S$. aureus pneumonia. Overall, the clinical features of animals in each bacterial strain treatment group were not significantly different.

\section{Characteristics of the Gross Pathology of the Infected Monkey Lungs}

As a first assessment of potential differences in virulence between wild-type and $\Delta p v /$ strains, we conducted visual inspection and manual examination of the lungs excised at necropsy. We scored lung pathology semiquantitatively in a blinded fashion using five criteria, each set to a scale of 0 to 1 , to give a minimum possible score of 0 and a maximum possible score of 5. Evidence of lower respiratory tract infection was present in all 12 monkeys, and a range of gross pathological features was observed in both strain treatment groups. Lungs taken from four animals had subtle changes such as mild hyperemia and focal consolidation, resulting in gross pathology scores that ranged from 1.0 to 1.5 (Figure 1, A, C, E, G, I, K, and $M)$. In comparison, the eight other lungs demonstrated marked changes including mottled discoloration of the pleura, hemorrhagic cut surface of the parenchyma, and diffuse consolidation, resulting in gross pathology scores that ranged from 2.5 to 4.5 (Figure 1, A, C, E, G, I, K, and $M)$. Although the right lung (inoculated side) was typically more affected than the left, bilateral changes were present in nearly all of the monkeys. Several lungs also had a markedly increased mass attributable to vascular congestion, edema fluid accumulation, and inflammatory cell infiltration. No suppurative pleural effusions, empyemas, or cavitations were seen. Importantly, the severity of gross pathology findings positively correlated with presence of the clinical observations described above. These gross pathological features mimic those observed in humans with mild to moderate $S$. aureus pneumonia. ${ }^{38}$ Overall, the mean gross pathology score for animals in each bacterial strain treatment group (wild-type and $\Delta p v l$ strain) at each time point and across all time points was not significantly different (Figure 1, A, C, E, G, I, K, and M).

\section{Characteristics of the Microscopic Pathology of the Infected Monkey Lungs}

We next conducted detailed microscopic examination of the lung tissue obtained at necropsy. Slides were scored by two pathologists working independently and blinded to the strain used and time of sacrifice for each animal. We established a scoring system with three criteria per slide, each set to a scale of 0 to 4 , to give a minimum possible score of 0 and a maximum possible score of 12 . All 12 animals had lower respiratory tract infection based on microscopic pathological features observed in both strain treatment groups at all three time points. Lungs from four animals had pathological changes resulting in scores that ranged from 2.00 to 4.00 (Figure 1, B, D, F, H, $\mathrm{J}, \mathrm{L}$, and $\mathrm{N}$ ). In comparison, lungs from the other eight animals had more pronounced changes resulting in scores that ranged from 4.25 to 8.25 (Figure 1, B, D, F, H, $\mathrm{J}, \mathrm{L}$, and $\mathrm{N}$ ). Overall, the mean microscopic pathology score for animals in each bacterial strain treatment group (wild-type and $\Delta p v /$ strains) at each time point and across all time points was not significantly different.

All 12 animals had histopathological evidence of mild to moderate, multifocal, multilobar, interstitial pneumonia (Figure 2, A-F). Many had features of acute pneumonitis, acute bronchiolitis, and acute vasculitis. Commonly observed features of the interstitial pneumonia included increased polymorphonuclear (PMN) leukocytes and lymphocytes, fibrin deposition, hyperemia with capillary distention and congestion, and proteinaceous debris in the alveolar septa. The foci of acute pneumonia contained intraalveolar PMNs and monocytes, trace alveolar hemorrhage associated with hemosiderin-laden macrophages, and edema fluid with fibrinous debris. Rare microscopic foci of single alveolar septal cell necrosis were also noted, but no overt abscesses, necrotizing alveolitis, or necrotizing pneumonitis was seen. Many lung sections also had nonspecific reactive features such as type II pneumocyte hyperplasia and epithelial desquamation. Rare clusters of Gram-positive bacteria were identified in areas with the highest concentration of PMNs. As indicated by their lower histopathology scores, animals from both strain treatment groups sacrificed at 8-day postinoculation had early evidence of infection resolution, in- 


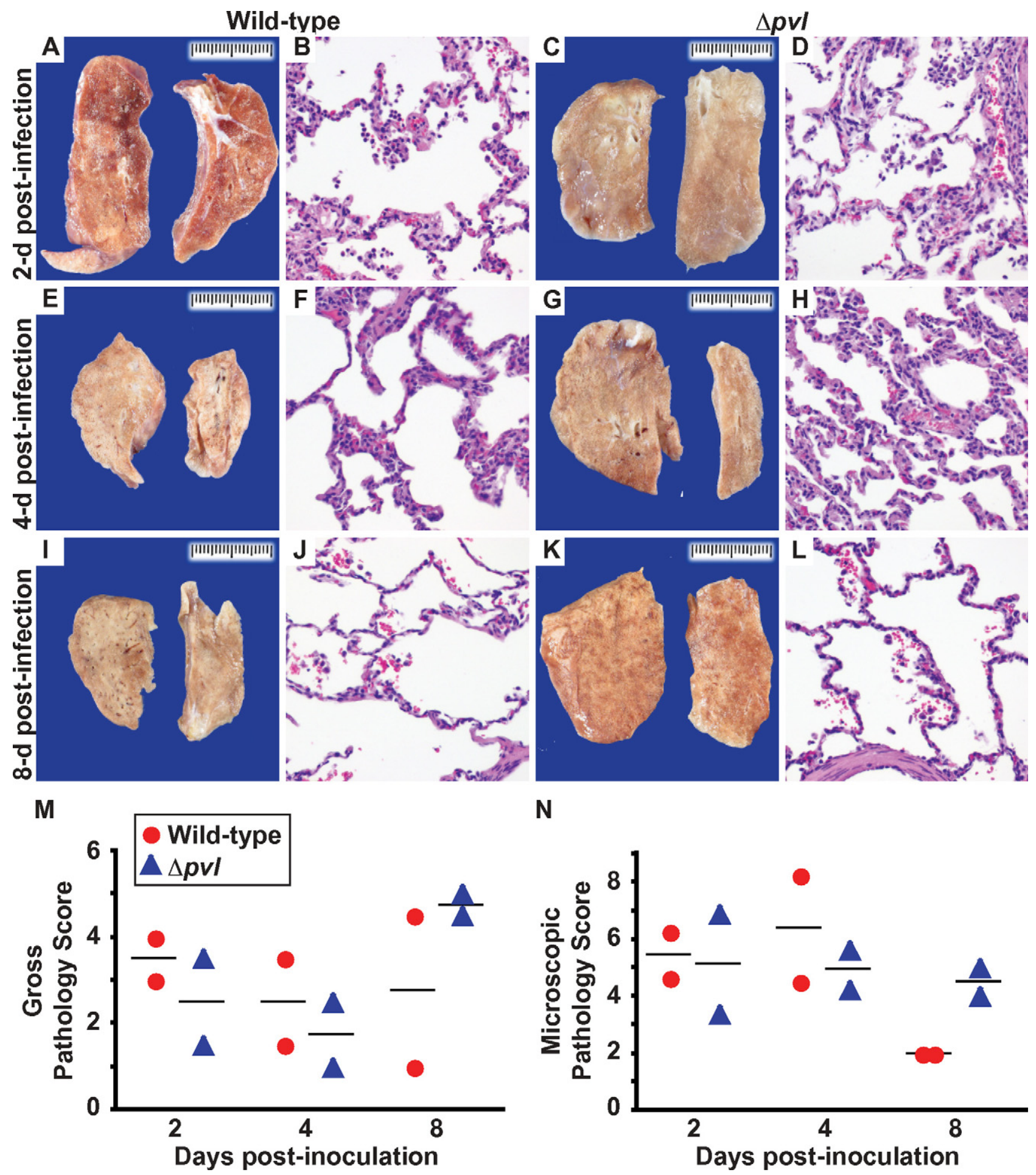

Figure 1. Gross and microscopic examination of cynomolgus macaque lungs infected with wild-type (left) or $\Delta p v l$ (right) strains of USA300. Similar histopathology features were observed in specimens collected at 2-day (A-D), 4-day (E-H), and 8-day (I-L) postinoculation (H\&E-stained section; original magnification $\times 20)$. Gross $(\mathbf{M})$ and microscopic $(\mathbf{N})$ pathology scores of monkeys infected with wild-type (red circles) or $\Delta p v l$ (blue triangles) strains of USA300 were not significantly different at any single time point (Mann-Whitney test, $P=$ not significant) or across all time points (one-way analysis of variance, $P=$ not significant).

cluding replacement of the acute inflammatory cell infiltrate with monocytes and tingible-body macrophages.

A prominent microscopic feature was the presence of IBALT (Figure 3, A-F). ${ }^{39,40}$ IBALT was invariably present in the right upper, middle, and lower lobe of all 12 ani- mals. It was also frequently present in the left lung lobes (contralateral to the side of $S$. aureus instillation). These ectopic lymphoid tissues had a particularly striking perivascular distribution, with as many as $25 \%$ to $50 \%$ of all small-to-medium-sized arterioles being involved in 


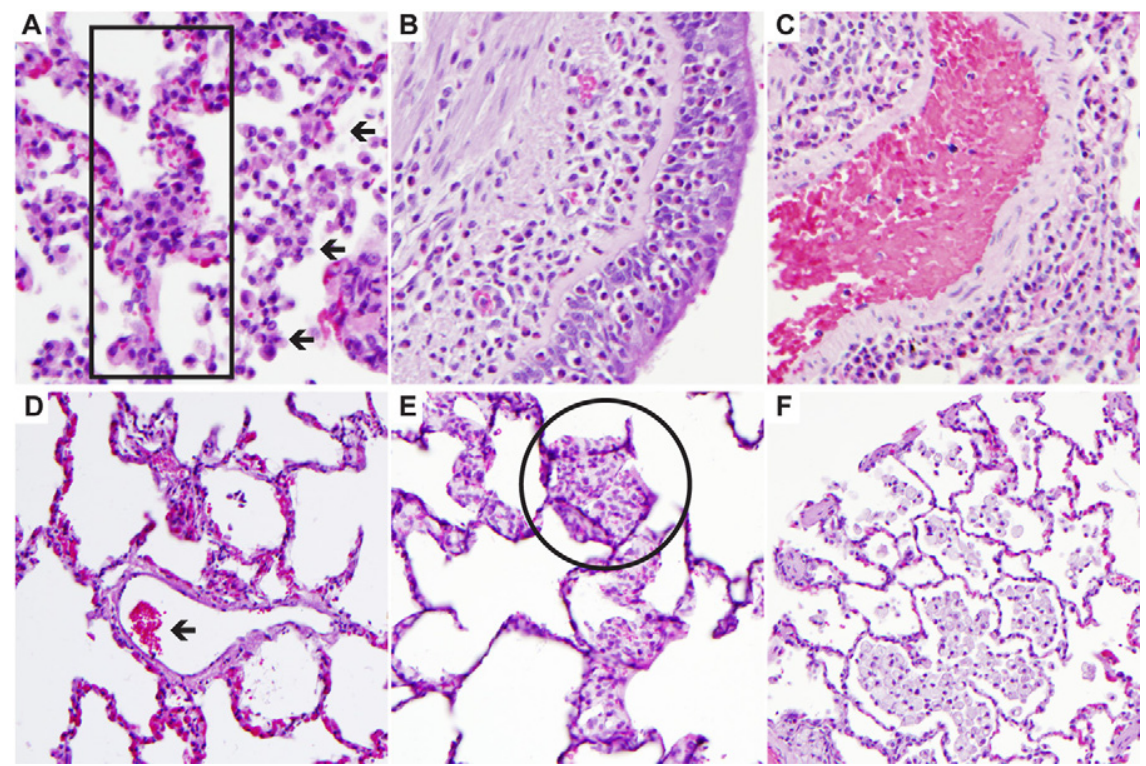

Figure 2. Microscopic examination of infected cynomolgus macaque lungs. Commonly observed features in animals infected with wildtype or $\Delta p v l$ strains of USA300 included mild to moderate pneumonia with increased inflammatory cell infiltrates, predominately PMNs and monocytes, in the interstitium (boxed region) and alveolar space (arrows; A), bronchiolitis (B), vasculitis (C), capillary vascular congestion with microhemorrhage (arrow; D), pneumocyte hyperplasia (circled region) with desquamation (E), and macrophages with abundant foamy cytoplasm (F; H\&E-stained section; original magnification $\times 40[\mathbf{A}-\mathbf{C}]$ or $\times 20[\mathbf{D}-\mathbf{F}])$ some specimens. Immunohistochemistry demonstrated that the IBALT was predominately composed of CD3+ T-cells. Scattered CD20+ B-cells, positioned individually and in small clusters, were also present within the loosely organized lymphoid structures. Rare-to-no CD21+ dendritic cells or CD38+ plasma cells were found. There was no difference in the size or volume of IBALT present in lungs infected with wild-type or $\Delta p v /$ strains.

\section{Microbiological Culture Assessment of Infected Monkeys}

Cultures of tissue homogenates prepared from the left lung (contralateral to the side of $S$. aureus instillation) recovered S. aureus from 6 animals (Table 1). Only one animal was bacteremic (Table 1). Isolates from the lung of one animal and the qualitative blood culture of another were confirmed to be MRSA. There was no evidence that the wild-type strain grew or disseminated to higher levels than the $\Delta p v /$ mutant strains.

Wild-Type and Isogenic PVL-Negative USA300 Strains Have Equivalent Pathology in Cynomolgus Macaque Lower Respiratory Tract Infection

To test the hypothesis that PVL contributes to virulence of USA300 in the lower respiratory tract, we compared

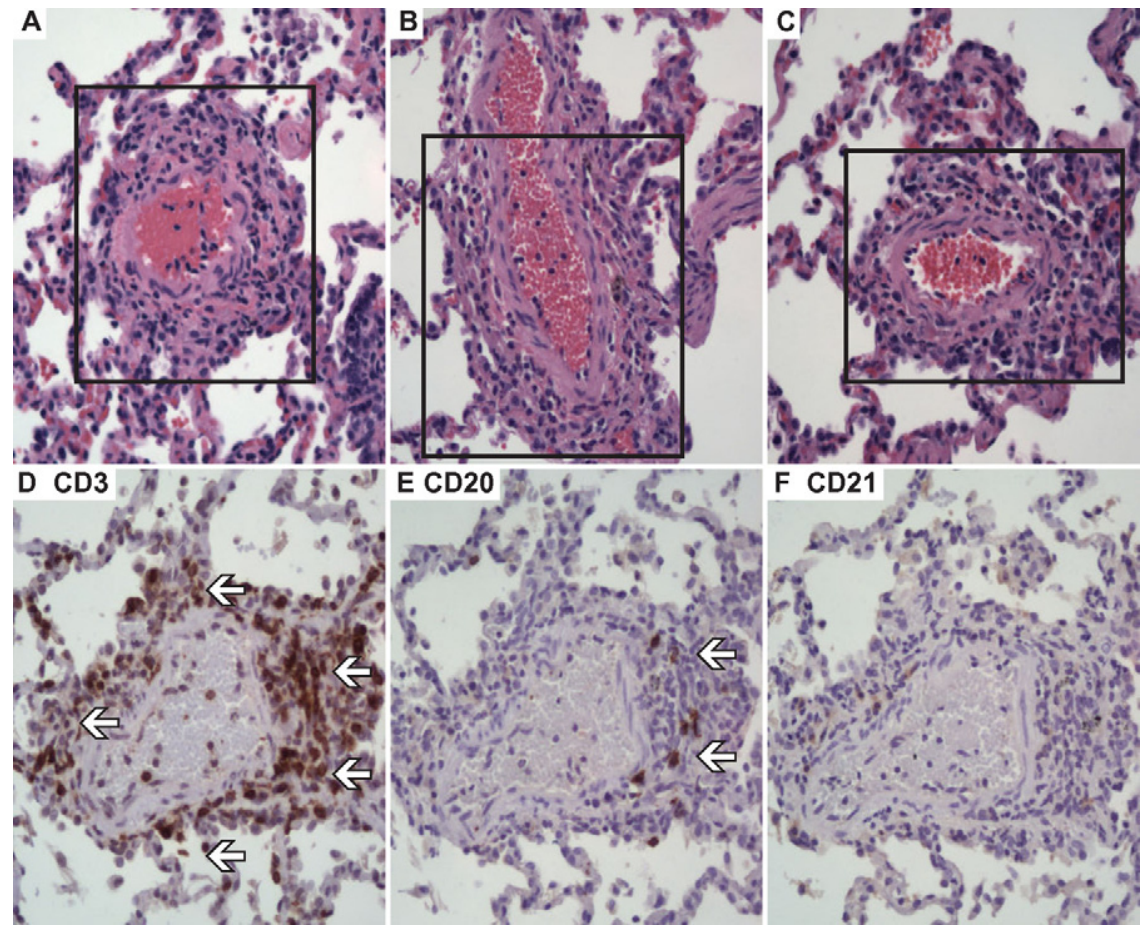

Figure 3. Perivascular cuffing of the small-tomedium sized arteries by induced bronchus-associated lymphoid tissue (IBALT). IBALT was observed in all animals at all time points, with three representative examples shown (A-C boxed region) (H\&E-stained section; original magnification $\times 40$ ). The lymphocytic structures consisted of many CD3+ T-cells (arrows; D) scattered CD20+ B-cells (arrows; E), and lacked a well-organized CD21+ dendritic cell meshwork (absence of positively staining cells; F; Consecutive sections cut from the same tissue block were stained with the $\mathrm{ABC}$ immunostain technique, DAB chromagen; original magnification $\times 40$ ). 
A

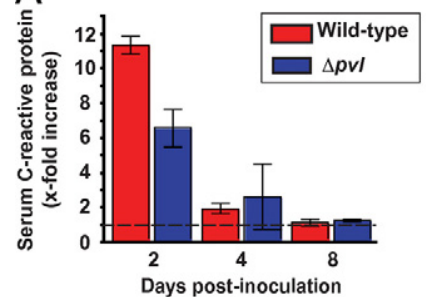

B

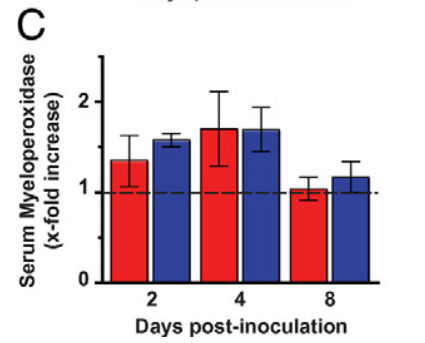

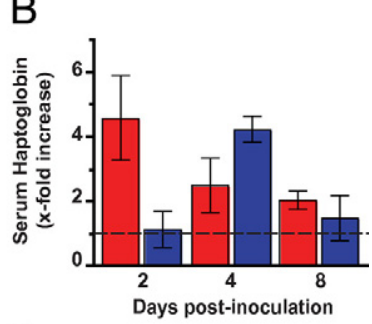

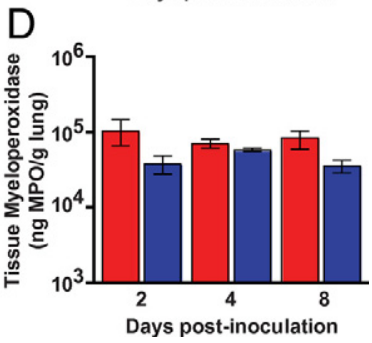

Figure 4. Cytokines and acute phase reactants were measured in the serum and tissue of infected cynomolgus macaques. Similar levels of serum C-reactive protein (A), serum haptoglobin (B), serum myeloperoxidase (C), and lung tissue myeloperoxidase (D) were found in animals inoculated with wild-type (red bars) or $\Delta p v l$ (blue bars) strains of USA300 (Mann-Whitney test, $P=$ not significant). The near-baseline levels of serum C-reactive protein and myeloperoxidase at 8-day postinoculation may be consistent with histological evidence of early infection resolution.

clinical and pathological features of monkeys infected with wild-type and $\Delta p v /$ strains at 2-day, 4-day, and 8-day postinoculation. None of the above-listed parameters of disease severity was significantly different between the strain treatment groups at any single time point or across all time points. Furthermore, lung tissue levels of myeloperoxidase, a PMN azurophilic granule enzyme and surrogate marker for PMN quantification, were equivalent in animals infected with either strain (Figure 4, A-D). Similarly, there was no significant difference between the strain treatment groups in the serum concentration of 89 cytokines, chemokines, and other bioactive molecules assayed with a Luminex based platform (representative analytes shown in Figure 4, and data not shown). That is, although all 12 of the monkeys developed a mild lower respiratory tract infection that mimics all clinicopathological features of human MRSA pneumonia, the wild-type and isogenic $\Delta p v /$ strains produced an indistinguishable pneumonia phenotype in cynomolgus macaques.

\section{Discussion}

Inasmuch as PVL has been postulated to have a role in virulence, we tested the hypothesis that PVL is a critical virulence factor for lower respiratory tract infection in nonhuman primates, an animal closely related to humans. We found no significant role for PVL in any parameter of disease severity measured, including fine-structure histopathology and host immunological response. Thus, in contrast to our expectation that was based in part on the many well-publicized PVL epidemiological studies, the data argue that PVL is not a primary virulence factor for lower respiratory tract infection caused by the USA300 clone. This conclusion

is consistent with previously reported data from several rodent pneumonia models. ${ }^{26-29}$ Furthermore, our experiment was carefully designed to detect very subtle pathological changes similar to those published in other molecular pathogenesis studies using nonhuman primates. ${ }^{41-43}$ We used a very large sample of monkeys, tissue examination at multiple time points, and a physiologically relevant inoculum of MRSA. Thus, it is highly unlikely that the observed absence of a major virulence effect of PVL is attributable to a limitation of the experimental design. However, it remains a distinct possibility that PVL only significantly contributes to lower respiratory tract disease in individuals with predisposing conditions such as respiratory virus coinfection or underlying medical perturbations. In support of this notion, fatal cases of CA-MRSA pneumonia, although rare, frequently preceded by an influenza-like illness. ${ }^{44,45}$ Moreover, review of autopsy materials collected during the 1918-1919 influenza pandemic concluded that most deaths occurred as a consequence of secondary bacterial pneumonia. ${ }^{46}$ Additional studies using this nonhuman primate model of CA-MRSA pneumonia are underway to test the hypothesis that PVL enhances pathogenesis during influenza virus coinfection. These studies are especially important in the context of the recent global spread of a $\mathrm{H} 1 \mathrm{~N} 1$ influenza strain and widespread concerns about a detrimental effect on human health. ${ }^{47}$

An unexpected finding of our investigation was the prominence of IBALT seen in the infected monkey lungs. IBALT was identified in nearly every specimen examined by microscopy (Figure 3). Compared with primary and secondary lymphoid organs that are embryonic structures that form in the absence of antigenic stimulation, IBALT and other ectopic Iymphoid tissues develop de novo in response to a specific antigenic encounter. ${ }^{48}$ This is an important distinction, because IBALT is thought to provide local protective immunity in the lower respiratory tract that is independent of the systemic immune response. ${ }^{39,40}$ Induced lymphoid tissues have been described in the lung, liver, and skin of humans, but they have not been previously described in monkeys. Our observation adds to the growing body of evidence that IBALT plays an important role in pulmonary defenses against invading microorganisms.

Our nonhuman primate data also have important implications for vaccine design. Because S. aureus resists intracellular killing by host PMNs after phagocytosis, ${ }^{49}$ new vaccine strategies that enhance the beneficial local immune function of IBALT may be important to study in this model. ${ }^{50}$

\section{Acknowledgments}

We thank Kevin R. Braughton (NIAID) and Adeline R. Whitney (NIAID) for preparing the bacterial inocula and characterization and/or verification of $S$. aureus strains. 


\section{References}

1. Klevens RM, Morrison MA, Nadle J, Petit S, Gersham K, Ray S, Harrison LH, Lynfield R, Dumyati G, Townes JM, Craig AS, Zell ER, Fosheim GE, McDougal LK, Carey RB, Fridkin SK: Invasive methicillin-resistant Staphylococcus aureus infections in the United States. JAMA 2007, 298:1763-1771

2. Moran GJ, Krishnadasan A, Gorwitz RJ, Fosheim GE, McDougal LK, Carey RB, Talan DA: Methicillin-resistant S. aureus infections among patients in the emergency department. N Engl J Med 2006 355:666-674

3. Noskin GA, Rubin RJ, Schentag JJ, Kluytmans J, Hedblom EC, Jacobson C, Smulders M, Gemmen E, Bharmal M: National trends in Staphylococcus aureus infection rates: impact on economic burden and mortality over a 6-year period (1998-2003). Clin Infect Dis 2007, 45:1132-1140

4. Styers D, Sheehan DJ, Hogan P, Sahm DF: Laboratory-based surveillance of current antimicrobial resistance patterns and trends among Staphylococcus aureus: 2005 status in the United States. Ann Clin Microbiol Antimicrob 2006, 5:2

5. Klevens RM, Edwards JR, Tenover FC, McDonald LC, Horan T, Gaynes $R$ : Changes in the epidemiology of methicillin-resistant Staphylococcus aureus in intensive care units in US hospitals, 1992-2003. Clin Infect Dis 2006, 42:389-391

6. Stewart GT, Holt RJ: Evolution of natural resistance to the newer penicillins. Br Med J 1963, 1:308-311

7. Chambers HF: The changing epidemiology of Staphylococcus aureus? Emerg Infect Dis 2001, 7:178-182

8. Fridkin SK, Hageman JC, Morrison M, Sanza LT, Como-Sabetti K, Jernigan JA, Harriman K, Harrison LH, Lynfield R, Farley MM: Methicillin-resistant Staphylococcus aureus disease in three communities. N Engl J Med 2005, 352:1436-1444

9. King MD, Humphrey BJ, Wang YF, Kourbatova EV, Ray SM, Blumberg HM: Emergence of community-acquired methicillin-resistant Staphylococcus aureus USA 300 clone as the predominant cause of skin and soft-tissue infections. Ann Intern Med 2006, 144:309-317

10. Baba T, Takeuchi F, Kuroda M, Yuzawa H, Aoki K, Oguchu A, Nagai Y, Asano K, Naimi T, Kuroda H, Cui L, Yamamoto K, Hiramatsu K: Genome and virulence determinants of high virulence communityacquired MRSA. Lancet 2002, 359:1819-1827

11. From the Centers for Disease Control and Prevention: Four pediatric deaths from community-acquired methicillin-resistant Staphylococcus aureus-Minnesota and North Dakota, 1997-1999. JAMA 1999, 282:1123-1125

12. Panton PN, Valentine FCO: Staphylococcal toxin. Lancet 1932 , 1:506-508

13. Zhang K, McClure JA, Elsayed S, Louie T, Conly JM: Novel multiplex PCR assay for simultaneous identification of community-associated methicillin-resistant Staphylococcus aureus strains USA300 and USA400 and detection of mecA and Panton-Valentine leukocidin genes, with discrimination of Staphylococcus aureus from coagulasenegative staphylococci. J Clin Microbiol 2008, 46:1118-1122

14. Zhang SX, Drews SJ, Tomassi J, Katz KC: Comparison of two versions of the IDI-MRSA assay using charcoal swabs for prospective nasal and nonnasal surveillance samples. J Clin Microbiol 2007 45:2278-2280

15. Kennedy AD, Otto M, Braughton KR, Whitney AR, Chen L, Mathema B, Mediavilla JR, Byrne KA, Parkins LD, Tenover FC, Kreiswirth BN Musser JM, DeLeo FR: Epidemic community-associated methicillinresistant Staphylococcus aureus: recent clonal expansion and diversification. Proc Natl Acad Sci USA 2008, 105:1327-1332

16. Liu C, Graber CJ, Karr M, Diep BA, Basuino L, Schwartz BS, Enright MC, O'Hanlon SJ, Thomas JC, Perdreau-Remington F, Gordon S, Gunthorpe H, Jacobs R, Jensen P, Leoung G, Rumack JS, Chambers HF: A population-based study of the incidence and molecular epidemiology of methicillin-resistant Staphylococcus aureus disease in San Francisco, 2004-2005. Clin Infect Dis 2008, 46:1637-1646

17. Diep BA, Gill SR, Chang RF, Phan TH, Chen JH, Davidson MG, Lin F, Lin J, Carleton HA, Mongodin EF, Sensabaugh GF, Perdreau-Remington F: complete genome sequence of USA300, an epidemic clone of community-acquired meticillin-resistant Staphylococcus aureus. Lancet 2006, 367:731-739

18. Purcell K, Fergie J: Epidemic of community-acquired methicillin-re- sistant Staphylococcus aureus infections: a 14-year study at Driscoll Children's Hospital. Arch Pediatr Adolesc Med 2005, 159:980-985

19. Hulten KG, Kaplan SL, Gonzalez BE, Hammerman WA, Lamberth LB, Versalovic J, Mason EO: Three-year surveillance of community onset health care-associated Staphylococcus aureus infections in children. Pediatr Infect Dis 2006, J:25:349-353

20. Miller LG, Perdreau-Remington F, Rieg G, Mehdi S, Periroth J, Bayer AS, Tang AW, Phung TO, Spellberg B: Necrotizing fasciitis caused by community-associated methicillin-resistant Staphylococcus aureus in Los Angeles. N Engl J Med 2005, 352:1445-1453

21. Francis JS, Doherty MC, Lopatin U, Johnston CP, Sinha G, Ross T, Cai M, Hansel NN, Perl T, Ticehurst JR, Carroll K, Thomas DL, Nuermberger E, Bartlett JG: Severe community-onset pneumonia in healthy adults caused by methicillin-resistant Staphylococcus aureus carrying the Panton-Valentine leukocidin genes. Clin Infect Dis 2005, 40:100-107

22. Lina G, Piemont $Y$, Godail-Gamot F, Bes M, Peter MO, Gauduchon V Vandenesch F, Etienne J: Involvement of Panton-Valentine leukocidin-producing Staphylococcus aureus in primary skin infections and pneumonia. Clin Infect Dis 1999, 29:1128-1132

23. Gillet $Y$, Issartel B, Vanhems P, Fournet JC, Lina G, Bes M, Vandenesch F, Piemont $Y$, Brousse N, Floret D, Etienne J: Association between Staphylococcus aureus strains carrying gene for Panton-Valentine leukocidin and highly lethal necrotising pneumonia in young immunocompetent patients. Lancet 2002, 359:753-759

24. Gonzalez BE, Hulten KG, Dishop MK, Lamberth LB, Hammerman WA, Mason EO, Kaplan SL: Pulmonary manifestations in children with invasive community-acquired Staphylococcus aureus infection. Clin Infect Dis 2005, 41:583-590

25. Labandeira-Rey M, Couzon F, Boisset S, Brown EL, Bes M, Benito Y Barbu EM, Vazquez V, Hook M, Etienne J, Vandenesch F, Bowden MG: Staphylococcus aureus Panton-Valentine leukocidin causes necrotizing pneumonia. Science 2007, 315:1130-1133

26. Montgomery CP, Daum RS: Transcription of inflammatory genes in the lung after infection with community-associated methicillin-resistant Staphylococcus aureus: a role for Panton-Valentine leukocidin? Infect Immun 2009, 77:2159-2167

27. Bubeck Wardenburg J, Schneewind O: Vaccine protection against Staphylococcus aureus pneumonia. J Exp Med 2008, 205:287-294

28. Bubeck Wardenburg J, Palazzolo-Ballance AM, Otto M, Schneewind O, DeLeo FR: Panton-Valentine leukocidin is not a virulence determinant in murine models of community-associated methicillin-resistant Staphylococcus aureus disease. J Infect Dis 2008, 198:1166-1170

29. Bubeck Wardenburg J, Bae T, Otto M, Deleo FR, Schneewind O: Poring over pores: alpha-hemolysin and Panton-Valentine leukocidin in Staphylococcus aureus pneumonia. Nat Med 2007, 13:1405-1406

30. Brown EL, Dumitrescu O, Thomas D, Badiou C, Koers EM, Choudhury P, Vazquez V, Etienne J, Lina G, Vandenesch F, Bowden MG: The Panton-Valentine leukocidin vaccine protects mice against lung and skin infections caused by Staphylococcus aureus USA300. Clin Microbiol Infect 2009, 15:156-164

31. Voyich JM, Otto M, Mathema B, Braughton KR, Whitney AR, Welty D, Long RD, Dorward DW, Gardner DJ, Kina G, Kreiswirth BN, DeLeo FR: Is Panton-Valentine leukocidin the major virulence determinant in community-associated methicillin-resistant Staphylococcus aureus disease? J Infect Dis 2006, 194:1761-1770

32. van Wamel WJ, Rooijakkers SH, Ruyken M, van Kessel KP, van Strijp JA: The innate immune modulators staphylococcal complement inhibitor and chemotaxis inhibitory protein of Staphylococcus aureus are located on beta-hemolysin-converting bacteriophages. J Bacteriol 2006, 188:1310-1315

33. Szmigielski S, Prevost G, Monteil H, Colin DA, Jeljaszewicz J: Leukocidal toxins of staphylococci. Zentralbl Bakteriol 1999, 289:185-201

34. Ohara-Nemoto Y, Haraga H, Kimura S, Nemoto TK: Occurrence of staphylococci in the oral cavities of healthy adults and nasal oral trafficking of the bacteria. J Med Microbiol 2008, 57:95-99

35. Voyich JM, Braughton KR, Sturdevant DE, Whitney AR, Said-Salim B Porcella SF, Long RD, Dorward DW, Gardner DJ, Kreiswirth BN, Musser JM, DeLeo FR: Insights into mechanisms used by Staphylococcus aureus to avoid destruction by human neutrophils. J Immunol 2005, 175:3907-3919

36. Kennedy J, Blair IS, McDowell DA, Bolton DJ: An investigation of the thermal inactivation of Staphylococcus aureus and the potential for 
increased thermotolerance as a result of chilled storage. J Appl Microbiol 2005, 99:1229-1235

37. Wang R, Braughton KR, Kretschmer D, Bach TH, Queck SY, Li M, Kennedy AD, Dorward DW, Klebanoff SJ, Peschel A, DeLeo FR, Otto M: Identification of novel cytolytic peptides as key virulence determinants for community-associated MRSA. Nat Med 2007, 13:1510-1514

38. Farver CF: Bacterial diseases. In: Zander DS, Farver CF, eds. Pulmonary Pathology. Philadelphia: Churchill Livingstone Elsevier, 2008:167-202

39. Rangel-Moreno J, Hartson L, Navarro C, Gaxiola M, Selman M, Randall TD: Inducible bronchus-associated lymphoid tissue (BALT) in patients with pulmonary complications of rheumatoid arthritis. J Clin Invest 2006, 116:3183-3194

40. Moyron-Quiroz JE, Rangel-Moreno J, Kusser K, Hartson L, Sprague F, Goodrich S, Woodland DL, Lund FE, Randall TD: Role of inducible bronchus associated lymphoid tissue (BALT) in respiratory immunity. Nat Med 2004, 10:927-934

41. Geisbert TW, Geisbert JB, Leung A, Daddario-DiCaprio KM, Hensley LE, Grolla A, Feldmann H: Single-injection vaccine protects nonhuman primates against infection with marburg virus and three species of ebola virus. J Virol 2009, 83:7296-7304

42. Kobasa D, Jones SM, Shinya K, Kash JC, Copps J, Ebihara H, Hatta Y, Kim JH, Halfmann P, Hatta M, Feldmann F, Alimonti JB, Fernando L, Li Y, Katze MG, Feldmann H, Kawaoka Y: Aberrant innate immune response in lethal infection of macaques with the 1918 influenza virus. Nature 2007, 445:319-323

43. Song XY, Fox F, Gallo MA, Rosenberg A, Jordan R, Shealy D, Wagner C: Effects of 2 different anti-tumor necrosis factor-alpha agents in a primate model of subcutaneous abscess formation. J Infect Dis 2002, 185:204-213

44. Hageman JC, Uyeki TM, Francis JS, Jernigan DB, Wheeler JG Bridges CB, Barenkamp SJ, Sievert DM, Srinivasan A, Doherty MC, McDougal LK, Killgore GE, Lopatin UA, Coffman R, MacDonald JK, McAllister SK, Fosheim GE, Patel JB, McDonald LC: Severe community-acquired pneumonia due to Staphylococcus aureus, 2003-04 influenza season. Emerg Infect Dis 2006, 12:894-899

45. Rubinstein E, Kollef MH, Nathwani D: Pneumonia caused by methicillin-resistant Staphylococcus aureus. Clin Infect Dis 2008, 46 Suppl 5:S378-S385

46. Morens DM, Taubenberger JK, Fauci AS: Predominant role of bacterial pneumonia as a cause of death in pandemic influenza: implications for pandemic influenza preparedness. J Infect Dis 2008, 198:962-970

47. Dawood FS, Jain S, Finelli L, Shaw MW, Lindstrom S, Garten RJ, Gubareva LV, Xu X, Bridges CB, Uyeki TM: Emergence of a Novel Swine-Origin Influenza A (H1N1) Virus in Humans. N Engl J Med 2009, 360:2605-2615

48. Carragher DM, Rangel-Moreno J, Randall TD: Ectopic lymphoid tissues and local immunity. Semin Immunol 2008, 20:26-42

49. Kennedy AD, Deleo FR: Neutrophil apoptosis and the resolution of infection. Immunol Res 2009, 43:25-61

50. DeLeo FR, Diep BA, Otto M: Host defense and pathogenesis in Staphylococcus aureus infections. Infect Dis Clin North Am 2009, 23:17-34 